\title{
Assessment of organizational and technological reliability of the construction company in the construction of foundations
}

\author{
Elena Mikhaylova ${ }^{1, *}$ \\ ${ }^{1}$ Moscow State University of Civil Engineering, Yaroslavskoe shosse, 26, Moscow, 129337, Russia
}

\begin{abstract}
When choosing a construction company, it is important for the investor to assess its organizational and technological reliability, which affects the duration and cost of construction. It is proposed to use as a source of information about the reliability of the data on the development of capital investments by the construction organization for a fixed period of time. The purpose of the study - to offer a mechanism for assessing the organizational and technological reliability of the construction company in the construction of the Foundation. On the basis of the method of variant design all possible alternatives of simple technological processes in the construction of pile foundations were considered. Using the method of statistical testing of simulation models on each process flow, the most probable duration and cost of design work were determined. All the options for the development of capital investments were reduced to a statistical series, on the basis of which the curve of accumulated probabilities was constructed. On the curve of accumulated probabilities it is possible to determine the probability of building foundations at the right time with the required value of the index of development of capital investments. Variant design of the construction process allows to develop simulation models of construction of any foundations, on the basis of which the curves of the accumulated probabilities of the indices of development of capital investments for each type of foundations are formed. These curves serve as the basis for the investor in determining the organizational and technological reliability of construction organizations.
\end{abstract}

\section{Introduction}

When choosing a contractor, it is very important for the investor to assess the level of its organizational and technological reliability, which allows to ensure maximum return on the use of construction equipment and production workers, to minimize construction time by reducing downtime of construction equipment and production workers, to reduce the cost of construction through the use of resource-saving technologies and modern building materials [1]. An important indicator of the reliability of the production process is the duration of production of construction products, which determines the construction time required for the production of construction products in the planned volume on the basis of the duration of

*Corresponding author: tranz-volga@ yandex.ru 
individual stages of construction or types of construction products and potential technical, organizational, technological and financial capabilities of the construction organization $[2,3]$. Therefore, for the investor in assessing the competitiveness of the construction company of practical interest is the prediction of the probability of completion of the construction of objects and complexes in a given period. For this purpose, statistical information is collected about the projects in which the construction and installation organization took part.

As the main source of information about the reliability of the construction company is proposed to use information about the speed of development of capital investments for a certain period. This is due to the fact that the duration of the individual stages of construction and their cost is calculated for specific organizational and technological solutions, which depend on the volume of work (in natural terms), the means of mechanization used, the variety of technological processes and regional features of construction $[4,5]$.

The purpose of the study - to offer a mechanism for assessing the organizational and technological reliability of the construction organization in the construction of the foundation.

\section{Materials and Methods}

With the help of the method of variant design all possible alternative technologies of simple technological processes in the construction of pile foundations are determined.

During the calculations used design and estimate documentation; enlarged indicators of replacement cost and the cost of construction and installation works; various types of standards (FER, TER, gesn, Enira, SNiP 3.01-85 "Organization of construction production", SNiP 1.04.03-85* (part II) "Norms of the duration of construction and reserve in the construction of enterprises, buildings and structures"), information about the price indices in construction.

\section{Results}

All types of construction and installation works consist of complex, complex and simple technological processes, organizationally and technologically related to each other [6].

Complex technological process is a set of simple and complex technological processes performed by workers of one specialty. A complex technological process is a set of several simple technological processes performed by workers of one specialty. Simple process - a set of a small number of technological operations performed by one or a group of workers with the use of homogeneous or similar materials. Technological operation-part of the process, performed by one or a group of workers using the same means of technical equipment of materials and products.

Organizational solutions are formed at the level of simple technological processes, taking into account the impact of destabilizing factors of regional features of construction, technical, technological, organizational, social and climatic.

Due to the fact that the duration of the individual stages of the construction process is a random variable, depending on the above factors, it is necessary to use the method of variant design [7].

To describe the operation of elementary processes the following initial parameters are used:

- time spent - the cost of the machine (working) time it takes to produce a unit volume of products (unit scope of work);

- productivity - the volume of production (work) per unit of time, is the inverse of the norm of time; 
- single rate of consumption of material resources-the cost of material resources (building materials, products, structures, etc.) on a single amount of work;

- unit prices - the cost of resource costs per unit volume of output (work performed);

- time-based rates (cost of machine hours, the cost of man-hour).

To form a database of initial data for organizational and technological design, normative, reference, methodological and scientific publications are used as sources of information.

Organizational decisions are formed on the basis of direct search of the technological decisions applied in the construction organizations taking into account the available Park of construction equipment. Constraints on labour and construction time provide for the full use of available machine resources and productivity workers, taking into account regional characteristics. The limit on the size of labor resources is determined by: the maximum number of workers on the capture; the maximum permissible value of labor resources on the specialized and object flow. The maximum allowable number of workers on the gripper is assigned at the rate of $100 \%$ of the use of the production of workers, taking into account the type of construction.

Restrictions of intensity of providing a construction site (private, specialized or object flow) with materials, structures and products are established as a result of the analysis of the capacity of the base of the construction industry in the region, as well as the solution of the transport problem.

The sequence of variant formation of organizational and technological solutions of construction works is as follows:

1) Decomposition of complex technological processes to the level of simple technological processes (determination of the work composition);

2) Identification of alternative technologies for technological processes;

3) Determination of alternative organizational and technological solutions of technological processes for each variant of the technology of works (options of possible organizational and technological solutions are formed, based on the available resources of the construction organization);

4) calculation of intensity of works for each variant of organizational and technological solutions of works;

5) Calculation of duration and cost of performance for each option of organizational and technological solutions of work.

The model of the object flow of construction as a whole is developed from the set of formed solutions. To do this, determine the most likely duration of work on each process flow using the method of statistical testing of simulation models [8].

Using the method of variant design, all possible alternative technologies for simple technological processes in the construction of pile foundations of a 9-storey brick house were identified, as well as possible solutions within each technology, determined by the composition of the available organizational and technological resources of the average construction and installation organization of the Volgograd region.

To design a schedule of construction within the plan of construction organization is required to develop the organizational and technological scheme of works on individual properties on the basis of the General strategy of land development. These schemes should be based on the flow method of construction organization, providing for the continuity of work of teams of contractors with the maximum combination of work at the facilities and facilities of the complex.

The critical path of the process of construction and installation works determines the duration of construction of residential buildings. The Directive term of commissioning of the analyzed object is defined in SNiP 1.04.03-85* (part II). This period for a 9-storey brick building with a total area of $12,000 \mathrm{~m} 2$ is 14 months: preparatory period-1 month, underground part-1 month, above-ground part-9 months, finishing-2 months. Accordingly, 
the months painted, what part of the estimated cost should be mastered for each month of construction. In accordance with the regulatory documents, the schedule of the estimated financing needs for the construction period was obtained.

The intensity of development of capital investments by periods in the variant design differs from the calculated schedule, therefore, as an indicator that characterizes the relative change in the development of capital investments from the calculated, the index of development of capital investments of $\mathrm{I}_{\mathrm{W}}$ was used:

$$
I_{W}=\frac{W_{f}}{W_{N}},
$$

where $\mathrm{W}_{\mathrm{f}}$ is the actual development of capital investment,

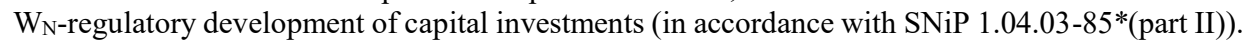

All the indices of development of capital investments is presented in table 1.

Table 1. Variant indexes of development of capital investments in the construction of pile Foundation of 9-storey brick house

\begin{tabular}{|c|c|c|c|}
\hline \multicolumn{4}{|c|}{ Variant indices of capital investment development, $\%$} \\
\hline 1 & 2 & 3 & 4 \\
\hline 102,43 & 105,29 & 103,19 & 107,64 \\
\hline 100,54 & 105,40 & 107,07 & 101,43 \\
\hline 112,82 & 101,13 & 100,62 & 110,85 \\
\hline 104,62 & 103,42 & 102,83 & 117,17 \\
\hline 119,95 & 103,33 & 111,12 & 95,31 \\
\hline 105,94 & 109,31 & 113,78 & 99,69 \\
\hline 110,78 & 104,41 & 109,87 & 98,62 \\
\hline 109,30 & 105,32 & 103,48 & 111,72 \\
\hline 107,32 & 98,84 & 105,46 & 106,21 \\
\hline 106,40 & 104,18 & 109,73 & 117,27 \\
\hline 105,43 & 105,21 & 113,44 & 109,17 \\
\hline 106,30 & 111,06 & 119,16 & 108,81 \\
\hline 102,43 & 105,29 & 103,19 & 107,64 \\
\hline 107,83 & 102,97 & 114,09 & 106,93 \\
\hline 105,74 & 97,82 & 110,44 & 107,08 \\
\hline 107,72 & 105,29 & 117,32 & 109,83 \\
\hline 108,59 & 100,36 & 111,57 & 102,75 \\
\hline 102,58 & 102,06 & 110,89 & 104,58 \\
\hline 117,25 & 105,23 & 105,26 & 112,99 \\
\hline 109,15 & 102,20 & 96,83 & 118,95 \\
\hline 102,83 & 97,34 & 98,73 & 106,88 \\
\hline 119,18 & 103,05 & 96,49 & 99,03 \\
\hline 106,71 & 99,94 & 112,28 & 116,96 \\
\hline 114,29 & 97,76 & 114,77 & 113,55 \\
\hline 109,97 & 103,22 & 109,25 & 106,62 \\
\hline 111,32 & 104,07 & 112,20 & 108,61 \\
\hline 103,96 & 99,12 & 109,05 & 107,44 \\
\hline 109,34 & 101,07 & 105,49 & 107,34 \\
\hline 103,31 & 105,21 & 106,39 & \\
\hline & & & \\
\hline
\end{tabular}

Based on the data in table 1, a polygon and a curve of accumulated probabilities are constructed (Fig. 1). 


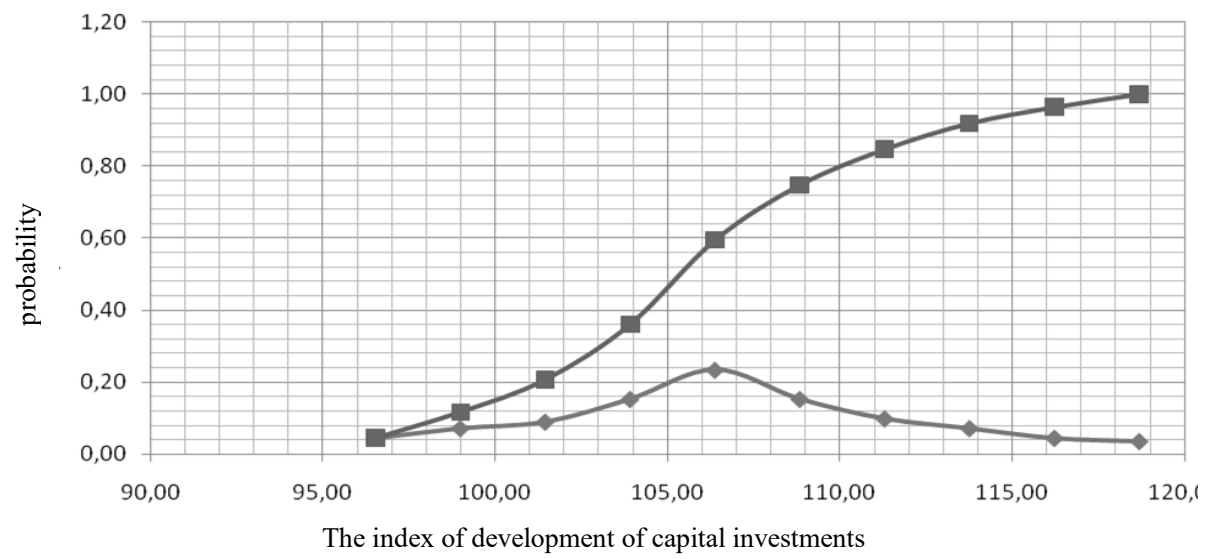

Fig. 1. The curve of the accumulated probabilities of variant indices of development of capital investments in the construction of the pile Foundation of a 9-storey brick house

On the curve of the accumulated probabilities it is possible to determine the probability of construction of an object with a given value of development of capital investments.

Monitor the value of capital investments and construction organization to determine its organizational and technological reliability associated with organizational difficulties and confidentiality of this information. In addition, the results of observations depend on the skills of workers, the use of equipment capacity, construction technology, climatic conditions, the quality of building materials, the quality of spare parts, etc. [9]. These factors do not allow to transfer the results of observations to other construction organizations without appropriate adjustments, which are that on the basis of primary information on the development of capital investments by the construction organization determine the theoretical law of distribution of the index of development of capital investments.

The calculations showed that the law of normal distribution can be used as a theoretical law of distribution of the variant index of development of capital investments.

\section{Discussion}

Gusakov A. A. believes that the probability of the construction of the real estate object in time should range from 0.6 to 0.75 [10].

Therefore, if the average value of the index of development of capital investments of a construction organization is above 0.75 on the curve of accumulated probabilities, its organizational and technological reliability is high, ranging from 0.6 to 0.75 - average, below 0.6 - low. The study showed that the average index of development of capital investments of construction and installation organizations of the Volgograd region is in the range from $106.87 \%$ to $109.84 \%$ depending on the type of residential building.

In this regard, it is proposed to construction and installation organizations submitting documents to participate in the contract auction to specify the cost and timing of the construction of five similar real estate objects.

Investor (customer) choosing a contractor, determines the index of development of capital investments for each object and if it is more than $106.87 \%-109.84 \%$, the organizational and technological reliability of the organization is normal, and it can be considered as a candidate for the contract. 


\section{Conclusions}

Variant design of the construction process allows to develop simulation models of construction of any objects in a particular region, on the basis of which the curves of the accumulated probabilities of the indices of development of capital investments for each type of buildings are formed. These curves serve as the basis for the investor in determining the organizational and technological reliability of construction organizations.

\section{References}

1. R. Simanaviciene, R. Liaudanskiene, L. Ustinovichius, Automation in Construction, 39, 47-58, (2014)

2. A. Ginzburg, Vestnik MGSU, 4, 251-255 (2010)

3. N. Shulzhenko, Y. Pushilina, D. Chubarov, Izvestiya of the Tula state University, 7-2, 152-157 (2016)

4. V. Kabanov, Engineering and construction journal, 1(77), 59-67 (2018)

5. V. Velichkin, Engineering and construction journal, 7, 74-79 (2014)

6. R. Gazaryan, V. Chulkov, K. Grabovyy, K. Kulakov, Vestnik MGSU, 3, 218-222 (2012)

7. V. Kabanov, E. Mikhaylova, Economics of construction, 4, 67-79 (2012)

8. V. Molodetskiy, A. Martysh, Bulletin of Prydniprovsk state Academy of civil engineering and architectures, 3, 8-14 (2013)

9. Y. Ivashenko, A. Ferder, Bulletin of the South Ural state University, 1, 34-37 (2017)

10. A. Gusakov, Moscow: Stroyizdat (1994) 